\title{
DEBATE EN TORNO A LA ACCION POPULAR
}

\begin{abstract}
"Hay acción popular ante el Poder Judicial contra los reglamentos y contra las resoluciones o decretos gubernativos de carácter general que infrinjan la Constitución o las leyes, sin perjuicio de la responsabilidad política de los Ministros. La Ley establecerá el procedimiento judicial correspondiente". (Art. 133, Const. 1933).
\end{abstract}

\section{Generalidades}

Creada en el siglo pasado, la Acción Popular se ha ido perfilando a lo largo del tiempo como una institución de verdadera importanciá en los países de América Latina, que son los que la han creado $y$ legislado. En nuestro país, aparece en la Constitución vigente como último numeral del Título "Formación y Promulgación de las leyes", sin que esté en referencia a la impugnación de éstas, ya que sólo cabe contra los actos o reglas del Poder Ejecutivo. La ubicación que le corresponde es dentro del Título "Poder Judicial", como una facultad que ante éste se concede para que declare la inconstitucionalidad o ilegalidad de determinadas disposiciones, tal como sucede en otras constituciones de América Latina; Colombia: Arts. 214-216; Cuba: Art. 194; Panamá: Art. $167 \ldots$...etc. Está tan mal ubicado, que José María Lezcano y Mazón en su obra "Constituciones Políticas de América Latina" (Tomo I, p. 99) creía que en el Perú al Poder Judicial no se le había concedido la facultad de declarar la inconstitucionali. dad de los reglamentos o disposiciones emanadas del Poder Ejecutivo, ya que ella no figuraba en título XIII de la Carta.

No sólo adolece de este defecto, sino que, además, a diferencia de otràs legislaciones más claras, nuestro artículo 133 origina, por su redacción escueta, múltiples problemas que no han sido esclarecidos debidamente $y$ algunos de los cuales trataremos.

\section{La Acción Popular como facultad ejercitada ante el Poder Judicial.}

En algunos países la custodia de la Constitución se encarga a Tribunales Especiales, diferentes a los comunes y que no dependen del Poder Judicial; en el Perú no se ha encargado la protección de lá Car. ta Magna a Tribunales de esta naturáleza, sino al Poder Judicial, ya que nuestra doctrina es, desde antaño, casi uniforme en aceptar que éste, y no aquéllos, es el más capacitado para velar por la Constitución. Pero existe una corriente doctrinaria que propugna la creación de un organismo especial con capacidad para declarar la nulidad de las leves $\checkmark$ cualquier otra disposición legal que infrinja la Ley Fundamental, a semejanza del sistema implantado en Austria en base a un proyecto del jurista Hans Kelsen, imitado por la República Española hacia el año de 1931, en Cuba en la Carta de 1940 . . etc., corriente que en el Perú cuenta últimamente con más adeptos $\vee$ propugnada por Bustamante y Rivero (1) y Ferrero Rebagliati (2), aduciendo este último que se bien los Jueces reunen la ventaja de su preparación jurídica, es conveniente mantener su alejamiento de la política. Aún cuando es respetable esta opinión, considero que no es conveniente cambiar el organismo competente para conocer de estas acciones, ya que, si bien el Poder Judicial carece de independencia absoluta respecto de quienes ocupan momentáneamente el Poder, un organismo jurisdicional "autónomo" llegaría a la postre a ser más dominado e incapaz de decidir cuestiones de tanta importancia de acuerdo al Derecho; $y$, la Corte Suprema, en caso de no tener el mismo criterio, estaría en la obligación de acatar lo ordenado por ese Tribunal Especial, con menoscabo de sus facultades de Poder del Estado.

(1) "El Proyecto de Reforma del Poder Judicial", en una separata de Visión del Perú en el Siglo XX; Lima; 1963; p. 121.

(2) "El Control de la Constitucionalidad de las Leyes", en Revista Jurídica del Perú: julio-setiembre de 1960; Lima; pp. 90-91 
Dentro del nombre genérico con que la Carta dice "Poder Judicial" debe entenderse que la competencia para resolver este tipo de cuestiones (vale decir la invalidez de disposiciones gubernativas de carácter general) está dada al Fuero Común, y den. tro de éste, a los Jueces civiles en sus diversas instancias, de modo que, actualmente, carecen de competencia los Fueros Especiales para resolver sobre la validez de dichas normas de diversa jerarquía $y$ no en los asuntos que las mismas pretenden regular. Por lo tanto, el Tribunal Agrario, por ejemplo, es incompetente para invalidar por inconstitucional o ilegal un Decreto-Supremo que verse sobre el abandono de tierras agrícolas, sin que ello implique, en modo alguno, recortar la facultad que tiene para no aplicarlo a un caso concreto, si lo considera contrario a las normas de superior jerarquía, al amparo, ya no det artículo 133 de la Constitución, sino de los artículos 8o. de la Ley Orgánica del Poder Judicial y XXII del Tít, Prelim, del Código Civil. Debe tenerse en cuenta, además, que el problema se plantea como un conflicto de normas y no como un problema propiamente agrario.

\section{Normas que pueden invalidarse.}

Las disposiciones legales secundarias que puede emitir el Ejecutivo a través de sus funcionarios son: el Decreto Supremo, la Resolución Suprema, la Ministerial y la Directoral, sin contar las Sub-Directorales, Circulares y otras, más que nada de organización interná. La Constitución otorga expresamente Acción Popular contra las resoluciones y decretos gubernativos de carácter general, entendiéndose como tales al Decreto y a la Resolución Supremos. Pero respecto a la Resolución Ministerial ¿cuál es el criterio a seguir?. El Constituyente tenía la idea, conforme a la doctrina, que éstas debían ser siempre de carácter particular y que, por ende, no debería caber la Acción Popular contra ellas, pero como en la práctica este sano criterio es inoperante $V$ se reglamentan cuestiones de carácter general por simples Resoluciones Ministeriales, éstas no pueden quedar eximidas de la impugnación por parte de cualquiera del pueblo, ya que, lo contrario, significaría, a no dudarlo, dar carta libre a un Ministro para que dicte reglamentos ilegales, con lo que se desvirtuaría la intención de la institución que nos ocupa, cual es controlar la labor reglamentaria del Poder Ejecutivo. Además, como el texto de la Constitución expresa simplemente resoluciones gubernativas, pueden bien comprenderse dentro de tal concepto las resoluciones expedidas por un Ministro. Problema semejante se presenta con las resoluciones directorales.

Otra posibilidad que se tiene contra dichas nor. mas es darlas a conocer al Congreso para que resuelva lo que viere conveniente (Art. 26 de la Constitución), sin perjuicio del derecho de petición ante el Ejecutivo para que derogue o modifique las normas inconstitucionales o ilegales.

En consecuencia, para la procedencia de esta ac. ción basta que la norma que expida el Ejecutivo tenga carácter general.

\section{Vigencia de las normas materia del conflicto.}

Al momento de incoarse la acción, tanto las normas emanadas del Poder Ejecutivo, como las disposiciones superiores vulneradas deben encontrarse en vigencia. Teniendo en cuenta que la acción materia de este artículo tiene como metas la protección de la Carta Fundamental y la legalidad, no se cum. pliría ningún objetivo al buscar la intangibilidad o amparo de una disposición Constitucional o legal ya derogada, o la nulidad de una norma legal secundaria que ha dejado de tener fuerza coercitiva $y$ que, por lo mismo, no viola el ordenamiento legal ni ningún derecho de la ciudadanía. Más aún, la sentencia invalidatoria sería meramente reiterativa.

La declaración de nulidad debe tener siempre en el fondo un objetivo, el que no se cumpliría si las normas en conflicto han perdido todo vigor; si se aceptase un criterio opuesto, la cuestión en debate sería meramente teórica, sin alcances prácticos $y$. por lo mismo, el interés público que sobre toda Acción Popular existe desaparecería y, en su lugar. se colocaría un mero capricho, un interés individual.

Las demandas que busquen semejantes pronunciamientos, por rebasar el ámbito de las acciones meramente declarativas, deben ser rechazadas de plano, puesto que la continuación del procedimiento resultaría, a la postre, banal; un debate inoficioso, que lo único que lograría sería perjudicar al actor con gastos $y$ tiempo que todo juicio demanda, así como recargar las labores de los jueces y Tribunales.

\section{Sustracción de materia.}

El Poder Ejecutivo puede en cualquier momento modificar o derogar las normas que él ha promulga. do como suyas. Es una facultad irrestricta que se le concede. 
Durante la tramitación de la Acción Popular, aún antes del fallo definitivo de la Corte Suprema, puede ocurrir tal delogación o modificación. Este hecho da lugar a que el Poder Judicial pueda pro. nunciarse sobre la validez del decreto impugnado, aún cuando la demanda haya sido oportunamente inter. puesta, puesto que la anulación ex-nunc de los Tribunales sería meramente reiterativa. En estos casos los jueces deben abstenerse de pronunciar un fallo de fondo, por sustracción de materia, como lo ha establecido en múltiples ejecutorias la Corte Suprema Colombiana (3).

Igual criterio debe aceptarse en el supuesto caso de que el decreto o resolución acusados hayan ad quirido fuerza de ley con posterioridad a la demanda o cuando las normas vulneradas se hayan modificado o derogado.

Pero en los casos en que además de la nulidad se haya solicitado la inaplicabilidad de la norma acusada, por existir interés de parte agraviada, debe admitirse este extremo de la demanda y declarar si fuere el caso que la norma es inaplicable al actor, ya que lo contrario sería un denegatoria de justicia y desamparo al actor en sus derechos.

$\mathrm{Si}$, en cambio, el Decreto o Resolución ha dejado de tener vigencia por haber sido anulado por el Supremo Tribunal, los Jueces pueden y deben no admitir esas demandas. A la contra-parte se le facultad, además, la posibilidad de deducir la excepción de cosa juzgada; pero téngase en cuenta que dentro de nuestro medio ella no está prevista. Pensamos nosotros, que tanto en éste como en todos los casos en que exista un vacío de la ley, deben aplicarse los principios del derecho, siempre que la analogía o la aplicación extensiva resulten insuficientes.

\section{Contra las Leyes o Decretos-Leyes.}

Si bien es verdad que la Acción Popular como instituto autónomo podría formularse también contra las leyes y así, en efecto, sucede en otros paises, en el nuestro está limitativamente restringida contra las normas emanadas del Poder Ejecutivo, dejándose la impugnación de las leyes librada a la resulta de otros medios. De la norma contenida en la Ley Fundamental se colige que el instituto de su materia está dado, precisamente, en favor de las leyes y no el caso contrario; esto es, para cuestionar su constitucionalidad.

- El criterio de no dar al Poder Judicial la facultad de declarar la nulidad de las leyes inconstitucio- nales es muy antiguo $y$ ya en el Ante-proyecto presentado en 1931 por Manuel Vicente Villarán se de. cía que el Poder que declurase la nulidad de una lye, adquiriría, por este hecho, superioridad jerárqui. ca sobre el Congreso; rechazando la forma anárquicá de control señalada en el artículo 100. de la Constitución de 1856 e instituyendo, en su artículo 142 , el llamado recurso de inconstitucionalidad ante el Poder Judicial. Juristas de renombre se han opuesto en nuestro medio a otorgar al Poder Judicial la posibilidad de declarar la nulidad de las leyes opuestas a la Constitución. Asi tenemos a Ulises Quiroga (4); Raúl Noriega (5); Carlos Sayán Alvarez, tanto en sus intervenciones como miembro de la Constituyente. como en sus discursos en calidad de Presidente de la Corte Suprema (6); Bustamante Cisneros (7): los miembros de la Comisión Prado que prepararon el Proyectu de la Carta de 1919; Anselmo V. Barreto, en la consulta que le formulara la Comisión Reformadora del Código Civil el 30 de junio de 1923; el informe de la Corte Suprema enviado a la Asamblea Constituyente el 14 de abril de 1932; y, el del Colegio de Abogados remitido a la misma Asam. blea ... etc.

A pesar de esta abrumadora mayoría que se opone a que el Poder Judicial pueda anular una ley $y$ que propugna $y$ sostiene la facultad del mismo para dejar de aplicar esas normas a un caso concreto, hay otros juristas que opinan de una manera diferentes $y$ son propulsores que la Acción Popular se amplie también contra las leyes a fin de obtener su nulidad. Pensamos que, además de las opiniones vertidas por los primeros, hay que tener en cuenta la falta de madurez cívica de nuestro pueblo y el hecho irrefutable de que nuestra vida jurídica está regida más por Decretos-Leyes que por Leyes. Si se ampliara el ámbito de la Acción Popular contra las yes, lógico sería que cabría también contra los De-

(3) "Gaceta Judicial"; Tomo. CXVIII; No. 2283; 40. Trimestre de 1966, p. 29.

(4) Memoria publicada en los Anales Judiciales de 1934; T. $X X X ;$ p. 400 y sig.

(5) Discurso publicado en los Anales Judiciales de 1950; T. XLVI: pp. 251-252.

(6) Diario de los Debates; T. VI; sesión del 6 de agosto de 1932; pp. 2726-2727; Además véase los Anales Judiciales de $1957 ;$ p. 300.

(7) Memoria publicada en los Anales Judiciales de 1960; T. LV; p.p. 387-388. 
cretos-Leyes, que sun las normas primarias que emiten los Gobiernos de facto para ordenar o reordena। un status determinado de cosas. Anularlos sería desconocer esta realidad y la posibilidad de entrar en un caos, que es precisamente lo que se trata de evitar.

Tampoce debe admitirse por los juzgados acción anulatoria contra los Decretos Supremos y Resoluciones que hayan adquirido con anterioridad al admisorio de la instancia fuerza de ley. Al respecto, tenemos la Ejecutoria de 25 de octubre de 1971 (Exp. No. 11-71), en la que se dice:

"CONSIDERANDO: Que al interponerse la demanda de fojas tres se encontraba en vigencia el Decreto-Ley número catorce mil cuatrocientos sesentidos, que dio fuerza de ley en todos sus efectos y a partir del primero de enero de mil novecientos sesentitrés, al Decreto Supremo número 12 S.G.M.G. -1, de dieciséis de octubre de mil novecientos sesentidos, por lo que carece de objeto todo y cualquier pronunciamiento sobre la eficacia legal o nulidad de dicho Decreto Supremo... DESAPROBARON . . . la sentencia en cuanto confirmando la apelada, declara nulo el Decreto Supremo número doce S.G.M.G.-1 de diecisés de octubre de mil novecientos sesentidos: reformando la primera y revocando la segunda en este extremo: declararon inadmisible esa parte de la demanda de fojas tres".

Este criterio debe servir también de guía para rechazar de plano toda Acción Popular contra normas legales emanadas del Poder Ejecutivo, haciendo uso de la legislación delgada, como es el caso de los Decretos-Supremos números 287-68 H.C. y 425-68 H.C., entre otros, puesto que dichas disposiciones legales no se han expedido al amparo del art. 154, inciso 8, de la .Constitución, sino en la permisión del Congreso al Ejecutivo para emitir normas legales primarias, capaces de derogar, modificar o ampliar las leyes existentes sobre determinada materia, de modo, pues, que sólo en su forma aparente dichos cuerpos. legales son Decretos Supremos. Siendo esto así y procediendo conforme a nuesțra actual Carta Política, la Acción Popular de que tratamos contra cualquier exceso del Ejecutivo, en tanto que ejercite la facultad reglamentaria, se descarta la posibilidad de que pueda, en base a la Acción Popular, anularse dichas disposiciones. Consideramos que si hubo exceso en la facultad de legislar en forma delegada, es el Congreso el que debe resolverlo, ya que al darse estas leyes extraordinarias, se precisa que el Poder Ejecutivo debe dar cuenta al Congreso Nacional de lo efectuado (Ley No. 17044) y es aqui donde se puede derogar total o parcialmente cualquier disposi. ción que rebase los límites sobre los que debió ac tuar.

Es menester hacer una atingencia: si bien la Acción Popular no cabe contra las leyes en sentido formal, ella funciona contra las leyes en sentido material (esto es, contra las diversas normas juridicas creadoras de derechos, obligaciones y sanciones; que otorgue facultades, las restrijna, amplie o modifique) puesto que un Decreto Supremo, Reglamento o Resolución que amplie, modifique o derogue una ley, lo que en realidad hace es legislar.

\section{Contra otro tipo de normas.}

En lo que se refiere a la impugnación de normas de carácter general emanadas de un Gobierno Local o de las expedidas por un organismo público con carácter general (como puede ser el Seguro Social del Peru), tampoco hay referencia expresa por parte de la legislación, para que se les pueda atacar en vía de acción pidiendo su nulidad. Por esto es que no cabe la Acción Popular contra las mismas. Y es que hasta el año de 1933, en que se dio la actual Constitución, la facultad reglamentaria sólo correspondia al Poder Ejecutivo, y no sucedía como ahora que diversos organismos dictan normas legales en calidad de reglamentos; de tal suerte que en aquél entonces no se pudo prever un alcance más amplio para la Acción Popular. Sólo hubo discusio. nes en el Congreso Constituyente sobre la impugna. ción de las resoluciones emandas de los Concejos Departamentales -que, dicho sea de paso, nunca han existido- que tuvieran eficacia amplia (8), pero la propuesta inicial del representante Hidalgo, no prosperó.

Considero que debe ampliarse la facultad concedida por el artículo 133 de la Ley Fundamental para que funcione ella contra todos los actos reglas de dichas entidades como sucede en otras Repúblicas que han legislado sobre la Acción Popular.

La doctrina se ha juesto en el caso de si es posible la impugnación de las leyes aprobatorias de

(8) Diario de los Debates; T. VII; sesión del 18 de octubre de 1932; p.p. $4352-4353$. 
Tratados y de las modificatorias de artículos de la Constitución. Con relación al primer punto, la res puesta ha sido dada por Ejecutorias de la Corte Su prema Colombiana en el sentido de que no cabe intentar Acción Popular contra aquéllas, puesto que, en el fondo, está en juego la voluntad de obligarse de 2 países. Dentro de nuestro ordenamiento legal, aprobándose los Tratados por Resolución Legislativa, que tienen la misma categoría que las leyes, no pueden ellos ser objeto de impugnación anulatoria.

Con relación al segundo punto, aún admitiendo la impugnación contra las leyes, no cabe la Acción Popular contra las que modifican artículos de la Carta Fundamentla, desde que aquéllas una vez promulgadas y publicadas, forman parte de la Constitu ción, resultando, por tanto, inimpugnables y más bien deben ser amparadas.

\section{Acción popular y legalidad.}

La Acción Popular protege el principio de la legalidad plasmado en los artículos 154, inc. 8o., de la Constitución y 8o. de la Ley Orgánica del Poder Judicial, entre otros. Sobre el particular, no cabe mayor análisis.

Siendo necesario preguntarse si un instituto es o no conveniente, es menester saber si en el caso de la Acción Popular, debe primar la protección abstracta a una ley cualquiera, por el mero hecho de verse vulnerada por un Decreto Supremo, Reglamento o Resolución gubernativa, o si debe darse preferencia a éstos sobre, por ser más favorables al pueblo o a los intereses dyla Nación. El problema no es utópico y como cuestionamiento teleológico de la acción que analizamos debe verse en todos los casos.

Han existido y existen leyes tendenciosas, obsoletas, deficientes o desadecuadas a una realidad social, política o económica que se vive. $Y$ puede suceder que el Poder Ejecutivo, tratando de remediar esta situación $y$ en vista de que el Congreso demora la dación de la ley pertinente, expida como Decreto Supremo una norma más adecuada o justa. Ante una situación como la propuesta, parece lógico que una situación como la propuesta, parece lógico que el mero quebrantamiento del ordenamiento jurídico por parte de una disposición gubernativa es suficiente causal para invalidarlo y que no puede permitirse esa oposición, así como tampoco es permisible que una sentencia judicial contrarie una ley. Puede argumeıtarse, igualmente, que si no atendemos ya a cuestiones puramente filidicis -vale decir la contra dicción existente entre 2 disposiciones legales de di ferente jerarquia- sino en lo referente a la bondad de la norma -como puede ser la necesidad de una disposición legal más adecuada a una realidad cam. biante- dariamos lugar a que el Poder Ejecutivo, amparándose en cuestiones de valores, amplie, modifique o derogue las leyes existentes, sustituyéndose at Congreso y compeliendo a la ciudadanía a cumplir sus prescripciones, con la facultad de imperium de que está investido, acaparando de este modo el Poder. Por lo tanto, no puede permitirse a este Poder del Estado que legisle. Aún más, si aceptamos este tipo de violaciones a principios formales del derecho $y$ que nos parecería saludable a primera vista, por ser más adecuadas o justas las normas emanadas al margen de la ley, daríamos pie a que el Ejecutivo, alguna vez, viole normas superiores, no en beneficio de la comunidad, sino en perjucicio de la misma. A mayor abundamiento, controlar la labor del Ejecutivo en base a la bondad de sus normas, además de ser difícil por la subjetividad que ello encierra, significaría lesionar, además, el principio de separación de poderes, toda vez que, por un lado, para modificar, ampliar o derogar las leyes existen. tes es necesaria otra ley, según el artículo 131 de la Carta y una ley sólo se deroga por una norma de igual categoría, a tenor de lo prescrito por el artícuto 10. del Tit. Prelim. del Código Civil, de lo que se deduce que no puede hacerse por un mero Decreto Supremo; y, por otro lado, como veremos, el Poder Judicial no puede controlar a tos otros Poderes del Estado en base al contenido y bondad de las normas que ellos expidan.

El Constituyente no podía poner, en modo al guno, a la Carta Magna - voluntad soberana de pue. blo- al mismo nivel de un reglamento, decreto o resolución gubernativa - voluntad del Presidente y uno o más Ministros- dándoles la posibilidad de que la restrinjan o la hagan inoperante. Tampoco les quiso otorgar la posibilidad de que estorbasen la labor del Legislativo y oponerse a sus prescripciones superiores en vía de reglamentación, atendiendo a que existe mayor seguridad para el pueblo de que se ha debatido en ambas Cámaras las leyes, lo que no sucede cuando un Consejo de Ministros delibera la dación de una norma legal secundaria.

Teriendo en cuenta el art. II del Tit. Prelim. del Código Civil que establece "La ley no ampara el abuso del derecho", ¿resultaría permisible que un ciudadano, haciendo uso de la facultad que le con 
fiere el artículo 133 de la Constitución, impugne de nulidad un reglamento, decreto o resolución que expida el Ejecutivo en beneficio de la comunidad? ¿Es saludable proteger el mito de la ley? Al respecto consideramos: a) que el Ejecutivo no puede sustituirse al Congreso; b) pero que si modificara, ampliara o derogara una ley por un mero acto gubernativo $y$ el Congreso considerase valioso dicho Decreto, debería darle fuerza de ley, como múltiples veces ha sucedido. Así, por ejemplo, tenemos el caso del D.S. No. 12 S.G.M.G.-1, de 16 de octubre de 1962, que adquirió fuerza de ley en base al Decreto-Ley No. 14462. c) El citado principio no resulta aplicable desde que prima la protección, el deber $y$ el derecho de todo ciudadano a la Constitución del Estado, que impide tales trasgresiones. d) el Poder Ejecutivo no puede irrogarse la potestad de decidir cuáles son las leyes obsoletas, tendenciosas o desadecuadas o modificarlas en el sentido que mejor le parezca, toda vez que, de admitirse ello, sería una facultad que conllevaría la trasmisión absoluta del Poder, primero, porque el Congreso queda relegado a un segundo plano al incumplirse sus normas; $y$, segundo. porque el otro Poder del Estado (Judicial) no está facultado para ser un censor de aquéllos, precisando la manera más conveniente en que se debió legislar, puesto que ello implicaria una facultad de decisión y mando, que rebasa el límite de las atribuciones que le confiere la Constitución y las leyes pertinentes. e) La ley vale por el hecho de haber sido expedida por el organismo designado por el pueblo y si se ajusta a la Constitución. Siendo esto asi, no pude ser vulnerada por cualquier dispositivo legal de inferior jerarquía, pero si sucediere el caso contrario, esto es, que se opusieran a la Ley Fundamental, y el reglamento, decreto o resolución gubernativo se ajustasen a la Carta Magna, obviamente debe darse protección a estos últimos y no a las leyes, desde que las leyes a las que se tutela es a las que guardan correlación con el ordenamiento jurídico, mas no a las otras, que, dicho sea de paso, en nada pueden obligar a un Poder del Estado.

En el año de 1948 se dictó el D.S. No. 774, mediante el cual se ampliaba la ley 10906, reprimiendo la reventa de entradas a espectáculos públicos como delito de especulación. Ejercitada la Ac. ción Popular contra el mismo al amparo de los artículos 57 de la Constitución y 2o. y 3o. del Código Penal, la Primera Sala Civil de la Corte Superior de Lima, expidió la siguiente resolución, el 8 de enero de 1974:

"VISTOS; con lo expuesto por el señor Fiscal, por sus fundamentos pertinentes; $y$; CONSIDERANDO: que el Poder Ejecutivo al extender, mediante el Decreto-Supremo número setecientos setenticuatro de ocho de octubre de mil novecientos cuarentinueve el ámbito de la especulación a la reventa de entradas a espectáculos públicos, ha obrado en armonía con la función tutelar que le corresponde, cautelando el interés social que resulta afectado por el jucro de quienes tratan de procurarse un provecho ilícito; que no se dan así los suspuestos requeridos por el artículo ciento treintitrés de la Constitución: CONFIRMARON la sentencia apelada... que declara improcedente la demanda...".

Sentencia contra la que no se hizo valer el recurso de nulidad, denegándose la elevación en consulta a la Corte Suprema. Quiere decir, pues, que a pesar de las argumentaciones anteriormente expuestas en este trabajo, el Poder Judicial permite que el Poder Ejecutivo legisle justo sobre aquellos puntos sobre los que hay reserva a la ley lcomo es el señalar los delitos $y$ las penas o imponer cargas tributa. rias): argumentando la necesidad de la norma legal tachada de inconstitucional o ilegal.

La Acción Popular es un instituto eminentemente constitucional, cuyo funcionamiento está en gran parte supeditado a la existencia de un gobierno constitucional, por existir allí los elementos necesarios para su subsistencia, tales como el respeto a la Ley Fundamental, la mayor autonomía del Poder Judicial respecto de quienes ocupan el gobierno y la separación de poderes, que permite el equilibrio $y$ coordinación de los mismos. No es ello óbice para que pueda hacerse valer durante un régimen de facto como el nuestro, pero siempre hay que tener en cuenta que no va a primar el respeto a una Ley opuesta al Estatuto del Gobierno Revolucionario o a las metas que éste persigue.

El artículo 5o. del Decreto-Ley No. 17063, expresa: "El Gobierno Revolucionario actuará conforme a las disposiciones del presente Estatuto y a las de la Constitución del Estado, leyes y demás disposiciones en cuanto sean compatibles con los objetivos del Gobierno Revolucionario". Entonces, pues, puede existir, como en el caso jurisprudencial expuesto, un Decreto Supremo compatible con los fines de la Revolución, que prime sobre un artículo 
de esta naturaleza, tanto porque no pueden intervenir por sí mismos en un proceso, cuanto porque la evolución mental de éstos no les va a permitir, espe-

\section{Legítimo Interés.}

Al hablar de Acción Popular, surge de inmediato el problema de saber si es o no necesario tener legítimo interés para acusar de inconstitucional a una determinada disposición legal y si es que sólo la parte agraviada está facultada para hacerlo o si puede interponerla cualquier ciudadano del pueblo. $\mathrm{Ni}$ el artículo constitucional que analizamos, ni su reglamentario, artículo sétimo de la Ley Orgánica del Poder Judicial, solucionan el problema.

Todo aquél que comparezca ante un Juez para ejercitar o contestar una acción debe tener legitimo interés moral o económico, sin el cual no puede solicitar nada del Poder Judicial; a esto se le denomina "Legitimatio ad processum". Pero este principio del derecho, recogido en el artículo IV del Título Preliminar del Código Civil, es válido sólo para aquellas acciones de naturaleza privada, o sea para las ejercitadas por quien pretende que se le reconozca un derecho, defenderlo o negar el que algue tener otra persona; principio que carece de sentido en las acciones públicas (tales como la que concede el artículo 76 del Código de Procedimientos Penales, el artículo 239 del Decreto-Ley No. 14250 o Estatuto Electoral, o el artículo 41 del Decreto-Ley No. 20680, llamado Estatuto de Prensa), puesto que en estos casos la ley la otorga a quisque de populo $y$, por lo mismo, no requiere que haya interés otorgado por la misma ley a cualquiera, por el solo hecho de ser miembro de la comunidad (9).

Capacita la Constitución a cualquier individuo. ¿Pero, a quiénes podemos considerar como miembros hábiles $\vee$ capaces de demandar por Acción Popular? ¿Todos pueden ejercitarla sin limitación? Vayamos por pasos. El término no ha sido debidamente esclarecido, y dada la amplitud que del mismo a primera vista se desprende, parecería que cualquiera que se encontrase en el Perú, podría ejercitar la Acción Popular. Consideramos que, para esclarecer el panorama y dar mayor solidez al instituto, es necesario hacer pequeñas restricciones, enmarcándolo así dentro de un cuadro más preciso y menos etéreo, interpretación que hacemos al amparo del articulo XXIII del Título Preliminar del Código Civil.

a) En razón de la persona no puede pensarse que los menores de edad o quienes carezcan de capacidad para obrar, puedan plantear una demanda cialmente en el caso de los interdictos por enfermedad mental, discernir claramente un caso de inconstitucionalidad o ilegalidad de una norma legal secundaria $y$ pedir su nulidad; pero ello no puede implicar que no puedan actuar por medio de curador o tutor $y$ solicitar, además de la nulidad, que les es inaplicable la norma que impugnen.

b) En razón del cargo o función, es necesario limitar el ejercicio de la acción no concendiéndola al Presidente de la República que dictó el Decreto gubernativo o Resolución, o a los Ministros de Esta do que lo firmaron o expidieron, ni a los que se encuentren en actual ejercicio de la Magistratura.

Tampoco deberían interponerla los Procuradores Generales de la República, puesto que la función de los mismos es la de defender al Estado y a la norma que se impugne y la etapa en la que les está permitido intervenir en un proceso por Acción Popular, no es al comenzar el mismo, -o sea entablando la demanda - sino al contestarla (10).

Los miembros del Poder Judicial con capacidad de decisión -esto es, los Jueces de cualquier categoría- tampoco pueden interponer Acción Popular, ya que la función de los mismos es la de definir el problema $\vee$ no el de proponerlo, sin perjuicio de la facultad que les confiere el artículo XXV del Título Preliminar del Código Civil. Igualmente, no es dable que los Representantes del Ministerio Público pretendan incoar acciones de este tipo, ya que su intervención en estos procesos no es la ser parte, sino auxiliares ilustrativos del Juez o Tribunal respectivo.

c) En razón de la nacionalidad serıa convenien te permitir la acción sólo a los nacionales. En lo

(9) Bielsa, Rafael... "Derecho Administrativo"; T.V; p.p. 139-143.- Calamandrei, Piero... "El Proceso Civil"; p. 155 párrato 2o.- Fix Zamudio Héctor... "Veinticinco Años de Revolución de la Justicia Constitucional"; p. 38.- Bustamante Cisneros, Ricardo... Memoria publicada en los Anales Judiciales de 1960; p. 376.- Ferrero Rebagliati, Raúl. "Garantías Constitucionales" en Derecho; 1969; No. 27; p. 39.

(10) Este principio ha sido plasmado ya en la Jurisprudencia Colombiana. Véase sobre el particular la Ejecutoria de 23 de noviembre de 1962, publicada en la Gaceta Judicial; T.C.; No. 2261-2264; setiembre a diciembre de 1962, p.p. 5-13. 
que respecta a los extranjeros, no parece saludable que se permita su interposición a los que se hallan de paso por el país, esto es a los turistas, desde que no se les considera como miembros permanentes de la comunidad $y$, por lo mismo, la anulación de la norma no los va a beneficiar ni directa ni indirectamente. Respecto del extranjero residente $y$ del domiciliado, sean personas naturales o jurídicas, por el hecho de considerárseles miembros más o menos permanentes de ia comunidad, debe permitírseles plantear la acción que faculta el artículo 133 de la Constitución, siempre que el petitorio no afecte a la ciudadanía.

Dentro de esta concepción amplia, no cabe, pues, suponer que sólo puede intentar la acción que nos ocupa quien ha sufrido un agravio real y concreto, como erróenamente sostiene Julio Ayasta Gonzales al expresar que “....cuando la Carta Política dice "Hay acción popular" queda entendida que es sólo a solicitud de parte interesada que se puede recurrir ante el Poder Judicial contra las resoluciones y leyes que lesionen intereses de particulares" (11), aún a sabiendas que en la mayor parte de los casos va a intentar la acción quien sea parte agravidad, puesto que, atendiendo a la naturaleza de la acción, no puede dejar de darse posibilidad a cualquiera del pueblo (que se percate de la incompatibilidad de dos normas de diversa jerarquía) para que impugne la inferior y se declare su nulidad; lo contrario sería negar el carácter de popular a la acción.

\section{Nulidad o no aplicación.}

Este es el punto fundamental del presente trabajo, pues. va a ser el que señale los alcances de este instituto $y$ del que se van a derivar cuestiones de suma importancia, tales como el determinar desde cuándo rige la declaratorio de nulidad.

La nulidad, en doctrina, puede ser de fondo, si se atiende a los derechos violados o en lo referente a la ampliación o modificación de los mismos. Puede ser de forma si se atiende a la manera de expedición del decreto o resolución o a la carencia de algún requisito fundamental: artículo 26 de la Ley de 26 de setiembre de 1862 y artículo 166 de la actual Constitución.

Respecto del problema en cuestión, existen dos posiciones antagónicas, por una de las cuales debemos tomar partido. La primera es apoyada por este articulo y que se pronuncia porque cuando la Constitución dice que hay acción popular contra los re- glamentos y resoluciones y decretos gubernativos de carácter general de la República, se refiere a que esa acción va a generar una sentencia anulatoria de la disposición tachada de inconstitucional o ilegal. La segunda, apoyada por un buen núermo de personas, sostiene que el efecto de dicha Acción Popular es tan sólo de declarar que no es de aplicación la norma legal a quien la impugne por infringir las prescripciones de rango superior.

No existe norma positiva que nos haga inferir, en forma indubitable, los efectos de la acción que se instituye en el artículo 133 de la Constitución. Es este el motivo por el cual (en base a razones de comodidad y temor, tanto porque mediante la primera se evitan problemas de rozamiento con otros Poderes del Estado $y$ se soslayan fuertes argumentos en favor de la tesis contraria, como porque el Poder Judicial muestra, una vez más, que es poco adicto a proteger sus fueros y a actuar conforme a sus preces) surge la posición de la inaplicabilidad. Posición ésta que carecería de sentido en otros paises, donde ni siquiera se cuestiona que la acción popular tiene como meta la sentencia que anule, por inconstitucional, la norma que se impugne, puesto que ya to tiene establecido no sólo la ley y la doctrina, sino también la jurisprudencia constante de los Tribunales. dad:

Fundamentos que sustentan la tesis de la nuli-

1.- La Acción Popular, aunque parezca nueva en su postulación es remota en su origen, puesto que nació en las primeras Constituciones del siglo pasado. Así, en la Constitución de 1823 (artículo 187) se indicaba "Todo peruano puede reclamar ante el Congreso, ante el Poder Ejecutivo o ante el Senado, la observancia de la Constitución y representar fundadamente las infracciones que notare", y si bien es verdad que sólo se concedía a los nacionales y no sólo procedia contra las normas legales, fue el primer embrión que conocemos sobre este instituto en nuestro país, ya que, era una facultad extensiva a cualquier peruano y su meta era la protección de la Constitución.

En la Carte de 1856 (artículo 10) se establecía que "Es nula y sin efecto, cualquier ley en cuanto

(11) Ayàsta Gonzales Julio... "Inconstitucionalidad de las Leyes" en Revista de Jurisprudencia Peruana; Lima; mayo de 1945; No. 16; p. 150. 
se oponga a la Constitución". Vale decir, que normaba un sistema anárquico de control de la constitucionalida de las leyes, puesto que no señalaba el órgano capaz de anularlas, la fecha desde la que regía la nulidad, el procedimiento para gestionarla o si es que era una nulidad ipso-jure. Tantos problemas generaba tan escueto $y$ deficiente dispositivo constitucional, que no se conoce como alguno en que se haya invalidado una ley al amparo de tal nora, ni que los tratadistas hayan analizado a fondo tal precepto, dando lugar a que no se reprodujera en las Cartas de 1860 ni en la de 1920.

El Proyecto Villarán, señalaba que "teóricamente es de toda evidencia la invalidèz de las leyes que infrinjan la Constitución, pero prefería la solución práctica llevada a cabo en los Estados Unidos de Norteamérica de reservar al Poder Judicial la potes. tad de no aplicar las leyes inconstitucionales en los casos sometidos a su jurisdicción habitual.

Ante la alternativa de aceptar uno u otro sistema, el Constituyente de 1931-1933 no aceptó la norma del artículo 10o. de la Carta de 1856, ni el recurso de inconstitucionalidad qque recién fue incorporado a la legislación en el Código Civil de 1936) y prefirió adoptar más bien un sistema ecléc tivo: se mantenía el criterio de la nulidad, pero no era una invalidez ipso-jure, sino que requeria una acción $y$ un organismo competente para declararla, previo análisis de las normas en colisión. Igualmente, el Constituyente pensó que no debería caber contra las leyes tal Acción Popular, sino tan sólo contra Reglamentos, Decretos y Resoluciones de carácter general, dejando escindido dicho instituto, de suerte tal que contra las leyes cupiese la Acción Popular ante el Congreso (artículo 26), para que éste conociere de la inconstitucionalidad de sus propias normas (artículo 123, inc. 4o.) y no otro Poder del Estado.

2.- El Constituyente conoció casos flagrantes de inconstitucionalidad que se tuvieron en cuenta para la redacción de los numerales 154, inc. 8o., y 133.

Del Diario de los Debates, fluye que lo que se pretendía era, precisamente, mantener el criterio de la nulidad y no simplemente el de otorgar a los jueces la facultad de no aplicar las normas inconstitucionales o ilegales, puesto que tal posición ni siquiera se pensó; antes bien, en la Sesión del día 6 de mayo de 1932 se analizó el actual artículo 154 inc. 80., (20, inc. 80., del proyecto) que decía "Son atribuciones del Presidente de la Repúbli. ca: ...80.) reglamentar las leyes y dictar decretos $y$ resoluciones". Las discusione's que surgieron para la redacción de este inciso son de suma importancia, pues al admitirse la hermandad de éste $y$ el artículo 133, nos damos clara idea de que el Constituyente tenia conciencia de que el Ejecutivo, bajo el pretex. to de reglamentar las leyes, las trasgredía. Vara $\mathrm{Ca}$ dillo (12) citó dos casos de reglamentos ilegales:

... el año de 1888 se dictó la ley que creó el Registro de la propiedad inmueble... El Poder ljecutivo al dictar el reglamento orgánico correspondiente, no solamente la completó en lo que tenia de deficiente, sino que en muchos puntos alteró substancialmente el espíritu de la ley dictada por el Congreso. Tenemos otro ejemplo reciente, señor Presidente, la ley que reduce la tasa de interés que deben cobrar las casas de préstamo. Esta ley se dictó en $1927 \ldots$ transcurrieron algunos meses hasta que un buen dia al Poder Ejecutivo se le ocurrió reglamentar la ley; y lo hizo autorizando, expresamente, a las casas de préstamos para que pudieran cobrar hasta el $10 \mathrm{o} / \mathrm{o}$ de interés mensual y fijando la tasa baja sólo cuando lo empeñado fuera alhajas, piedras preciosas y objetos de arte

El doctor Matias Manzanilla robusteció esta afir. mación agregando:

"Debemos recordar que ya alguna vez, hace treinta años se dictó un gran decreto sobre orden público y el Cobierno mantuvo aquí en el seno del Parlamento por el año de 1890 , que los reglamentos eran dados conforme a la Constitución y que, en consecuencia, el Poder Legislativo carecía de facultad para anularlos. Y hubo debates y grandes cuestiones alrededor de este punto, consignándose al fin, que se declaraba que el Poder Legislativo tenía soberanía para acabar con los reglamentos que los gobiernos habian dado invocando el texto de la Constitución.

Después, ha habido otra clase de reglamentos como los de policía minera, de locación de servicios de minas, completamente atentatorios a la Constitución, a la ley de trabajo y hasta a la dignidad humana, sin embargo, durante mucho tiempo surtieron (sus efectos)... Ha habido

(12) "Diario de los Debates"; T. III: p. 2495. 
otros reglamentus, por ijemplo, como el de ferrocarriles, en el que llegó a establecerse que la jornada de trabajo era de 16 horas, contra el espíritu de la Constitución y en contra de textos claros de nuestra ley. Ha habido reglamentos como los que conciernen a los accidentes de trabajo, en los que se establece de modo seudo-cient ífico la incapacidad absoluta, con lo que evidentemente, se ha abolido el espíritu de la ley reparadora de los infortunios del trabajador. Ha habido, por fin, casos más graves, en los que las leyes han venido aquí, al Parlamęnto. con articulos propuestos por el Gobierno...".

en los que pese a que las Camaras después de largos debates no aceptaron las propuestas del Ejecutivo, en los reglamentos de las leyes respectivas, volvieron a resurgir las propuestas del Gobierno (13).

3.- Estas mismas violaciones que se narran permitieron no sólo mejorar la redacción del artículo 154, inc. 8o., sino que sirvieron de fundamento pa. ra la. creación del articulo 133 de la misma Carta.

4.- Estas razones, que hasta el momento no nos dan plena seguridad de los reales alcances que se pensaba otorgar al instituto que se creaba, vienen a robustecerse plenamente con la intervención del representante por Piura, Castro Pozo. El pensamiento que iluminó al Constituyente está plasmado en la intervención que hizo aquél al debatirse el proyectado art. 154, inc. 8o., puesto que su opinión no fue en momento alguno opuesta a la de los demás Tribunos; antes bien, estuvierori concordes con su intervención. Decía este reirresentante:

"EL señor Bustamante de la Fuente manifiesta que en el articulo a que hace $r$ ferencia -que todavia no está aprobado - se establece que los decretos, resoluciones y reglamentos que no estén conformes al espiritu de la Constitución y de las leyes son nulos y que esta nulidad puede obtenerse por denuncia, a solicitud de cualquier ciudadano. Pues bien, este art. está en íntima relación con el inciso que se discute... de manera que todos aquellos decretos, resoluciones y reglamentos que estén fuera de esta disposición, podrán ser denunciadnc nara que queden nulos". (14).

El artículo a que se refería Castro Pozo era el numeral décimo del Provecto (que corresponde al actual 133) y presentado el día 12 de abril de 1932 con un texto casi idéntico al aprobado, ya que sólo se dejó a un posterior estudio la posibilidad de incluir dentro del mismo a las resoluciones de carácter general, en base a la propuesta del representante Juan José Hidalgo.

Entonces, pues, tenemos claro que en los debates de dicho Congreso se pensaba que el alcance de la Acción Popular que se creaba era el de anular la norma inferior colisoria.

5.- Pero no solamente en los debates encontramos ese criterio, sino también en los fundamentos escritos que se presentaban. Asi pues, al presentar la Comisión de Constitución al seno del Congreso el artículo 100. (hoy 133) indicaba:

"Con ocasión del ejercicio por el Poder Ejecutivo de la facultad que constitucionalmente tiene de reglamentar las leyes, se ha expedido multitud de disposiciones reglamentarias que infringen la Constitución o las leyes. La experiencia aconseja poner límites a la actividad gubernativa cuando rebalsa sus límites propios, en agravio de quienes por alguna razón son afectados por dichas resoluciones. La Constitución que es la ley matriz de la República debe ser celosamente defendida. Ningún reglamento que infrinja la Constitución o la ley tiene fuerza coercitiva $y$ cualquiera del pueblo, puede y debe denunciarlo ante el Poder Judicial, sin que esta acción popular impide o limite la acción del Parlamento para responsabilizar políticamente a los Ministros.

Disposición de tanta importancia, que figura por primera vez en nuestra Carta Política, reclama una ley que establezca el procedimiento judicial correspondiente" (15).

6.- Aún admitiendo que ni las razones históricas ni las discusiones en el Congreso Constituyente son suficientes para corroborar la tesis que se propugna, no podemos dejar de lado las enseñanzas de los juristas. Al respecto, aún cuando hay discrepancia entre ellos sobre el particular, un gran número se inclina por la tesis de la nulidad. El ex Presidente de la Corte Suprema Ulises Quiroga, fue el primero en

13) Op. cit.; p.p. 2491-2492

(14) Op. cit.; p. 2493.

(15) Op. cit.; Sesión del 12 de abril de 1932; p. 2621. 
referirse a este institulo y sefialaba que el artículo 133 de la Carta importa revisar los actos del Poder Ejecutivo $y$ que, como consecuencia, se extiende hasta revocar total o farcialmente las resoluciones que expida en el ejercicio de sus propias atribuciones; que ese dispositivo no era la manera correcta de solucionar el problema de la inconstitucionalidad, sino que más bien debió haberse aceptado el artículo 142 del Proyecto Villarán, que establecia el recurso de inconstitucionalidad.

Otro ex Presidente del Supremo Tribunal, Domingo García Rada, se suma a esta posición desde el momento que señala que el artículo 133 de la Ley Fundamental ". . . concede el ejercicio de la acción popular para denunciar la existencia de esa incompatibilidad y pedir que la ley, reglamento o decreto sea derogado". Aún cuando en nuestro medio dicho instituto no funciona contra las leyes $\mathrm{y}$ el efecto sea el anulatorio $y$ no el derogatorio, el planteamiento es el mismo que sostuvo Ulises Quiroga.

Félix Navarro Irvine también propuso en forma particular que la Acción Popular debia tramitarse por la via ordinaria, como proceso de puro derecho, a fin de solicitar la declaratoria de nulidad (16).

Carlos Sayán Alvarez opinaba que una institución de este tipo no era recomendable contra las leyes, tanto por ser extraña, cuanto por originar la anulación de la disposición legal tachada. (17).

Bustamante y Rivero sustenta su punto de vista en el sentido de que la Acción Popular, como medio de control jurisdiccional de las leyes, necesaria en nuestro ordenamiento jurídico, origina una sentencia de alcances generales; esto es, anulatoria de la norma legal inconstitucional $y$ que, por lo mismo, beneficia a la colectividad entera.

Dale Furnish en " $L a$ jerarquia del ordenamiento jurídico peruano", publicado en la Revista Derecho, No. 30, 1972, sostiene que la Acción Popular parece estar dada, más que para rechazar la aplicación de las normas secundarias ilegales o inconstitucionales, en casos concretos, para anular esos actos ejecutivos.

Ferrero Rebagliati, señala:

"Precisamente quienes redactamos la actual Ley Orgánica del poder Judicial ... hemos pensado en que la sustanciación ordinaria pero no dilatada que corresponde al proceso de puro derecho garantiza decisiones judiciales cuyo alcance ha de ser general, como el interés que promueve la acción de parte de cualquera "de los del pueblo"... (18).

Vale decir, pues, que un gran número de estudiosos del derecho, estando o no de acuerdo con la Acción Popular, no dudan que los efectos de ella sean los de invalidar de modo general la disposición acusada.

7.- Precisa, también, considerar las opiniones de las comisiones de legislación, $Y$ asi, pues, la nombrada por Resolución no. 30 y 19 de abril de 1952. encargada de preparar un ante-proyecto de Ley Orgánica del Poder Judicial, propuso en su artículo noveno que podía acudirse a la jurisdicción común a fin de solicitar ". ... la nulidad de las disposiciones gubernativas de carácter general contrarias a la Constitución o a las leyes".

Otro proyecto de la propia ley preparado por la comisión creada por el artículo 14 de la Ley número 13036, estatuyó en su art. 7o. que la Acción Popular cabia contra las personas jurídicas de derecho público, para solicitar la declaratoria (genérica) de inaplicabilidad de las disposiciones que se considerasen contrarias a la Carta Fundamental o a las leyes.

Por último, alguno de los miembros de la comisión reestructuradora de ese anteproyecto, propusieron otorgar a la Sala Plena de la Corte Suprema la facultad de conocer de la Acción Popular que se reglamentaba, con intervención del actor y del Procurador General de la República y que la resolución que se expidiese, tendría por virtud dejar sin vigor ni efecto las leyes inconstitucionales - lo que importaba modificar la Constitución- y los reglamentos, decretos y resoluciones de igual carácter.

Criterio opuesto a toda esta corriente, sostienen los miembros de la comisión revisora del ante-proyecto de la Ley Orgánica del Poder Judicial $y$, al parecer, el doctor Bustamante y Cisneros. Los miembros de esa comisión en su informe de fecha 6 de junio de 1963 argüían que:

(16) Navarro Irvine, Félix... "Discursos, Memorias y Proyectos para el Colegio de Abogados"; Lima; 1954, p. 212. (17) Memoria publicada en los Anales Judiciales de 1957: p. 299.

(18) "Garantías Constitucionales" en Derecho; No. 27; p. 39. 
“... no parece saludable ni realista colocar a la Corte Suprema en una eventual oposición frente al mandato popular, con los riesgos de una jurisprudencia desconcertante, o lo que es pero, de una reacción de los Poderes políticos en agravio de la majestad e independencia del Poder Judicial ... Desde luego la declaración judicial debe limitarse al caso "sub-judice" y no opere directamente con amplitud "erga omnes" porque ello sería atribuir al Poder Judicial la categoría de un super-poder, en desmedro de los otros poderes cuyo mandato emana directamente del voto popular" (19).

Esta opinión no se compadece con el espíritu y letra de la Constitución y olvida las disposiciones pertinentes de la Ley de Ministros del siglo pasado.

8.- El criterio de que el Poder Judicial no puede anular una norma reglamentaria al sentenciar una Acción Popular fue recogido por la Ejecutoria Suprema recaída en el procedimiento seguido por Arias Fiscalini con el Supremo Gobierno (20), en la que explícitamente se dijo, sin aceptar la opinión del Fiscal que se pronunciaba por la nulidad de la norma colisoria:

“... que 1a acción popular que establece el artículo ciento treintitrés de la Carta Fundamental tiene como finalidad declarar judicialmente que determinada disposición reglamentaria infrinja la Constitución o las leyes; que la resolución que se expida al respecto no puede invalidar de modo general la norma reglamentaria impugnada, sino sólo establecer que no es de aplicación en cuanto afecta derechos en determinados casos...".

Sin embargo, meses después, la propia Corte Suprema cambió de parecer (21), puesto que con fecha 28 de agosto de 1968, declaró nulos e inaplicables los Decretos-Supremos acusados por el ciudadano Carlos Orbegoso Barúa, aceptando el parecer del Fiscal Ponce Sobrevilla, que también dictaminó en el caso anterior. Esta última resolución nos viene a suministrar el más moderno criterio que al respecto existe en la Corte Suprema y concorde con el que se sustenta en el presente trabajo. Al respecto, debe considerarse que no se cambió de criterio sin conocer los antecedentes, sino que, antes bien, se oyó a las partes sobre el particular, resolviéndose después de una ardua discusión. El Procurador General de la

84
República, Daniel Amézaga Carranza, en su escrito presentado ante el Supremo Tribunal, fundamentando la alzada, expresaba:

“. . la demanda sería también improcedente puesto que se trata de la impugnación de normas de carácter general que no afectan o lesionan derechos del demandante.

El demandante en ningún momento manifiesta que tales disposiciones le hayan afectado algún derecho... Luego, si no ha sufrido daño alguno, es obvio que no le asiste derecho para reclamar... el sustento de toda acción es el interés que debe tener, necesariamente, el sujeto actor... en base a tal principio y norma legal, la Corte Suprema de la República tiene establecido por la Ejecutoria de 10 de noviembre de 1967. que la resolución judicial que recaiga en una acción ejercida al amparo de lo dispuesto en el artículo 133 de la Carta Fundamental, no pude invalidar de modo general la norma reglamentaria impugnada, sino únicamente establecer que ésta no es de aplicación, pero sólo en 'cuanto lesiona o afecta derechos en determinados casos". (22).

Concluyendo que conforme al artículo IV del Tit. Prelim. del Código Civil, no tiene el demandante legítimo interés $y$, por tanto, no está capacitado para demandar la invalidez de la norma acusada.

Ejecutoria que encuentra antecedentes en las resoluciones del propio Tribunal expedidas con anterioridad, tales como:

a) Exp. No. 133-60. Ante El Habeas Corpus presentado por la firma Sistemas Mecanizados Sociedad Anónima, contra el Decreto Supremo de 9 de enero de 1959, que aumentó en un 200 o/o el recargo en los derechos de importación correspondientes a la

(19) "Ley Orgánica del Poder Judicial" publicada por la Facultad de Derecho de la U.N.M.S.M.; 1965; p. 83.

(20) Exp. No. 207-67; La ejecutoria ha sido publićada entre otros lugares en la Revista de Jurisprudencia Peruana: No. 286 ; p.p. $1349-1351$

21) Lo que merece resaltar que ambas sentencias han sido firmadas por Vivanco Mujica, Peral y Carranza.

(22) Véase el cuadernillo No. 194-68, procedente de Lima; Primera Sala Civil; Archivo de la Corte Suprema de Justicia. 
partida número 1297 de la Tarifa de Importación que comprende el llamado "papel carbón", alegando su inconstitucionalidad por fomentar el monopolio y atentar contra la libertad de comercio e industria, la Corte Suprema de Justicia con fecha 28 de octubre de 1960 declaró sin lugar dicha acción, puesto que "la única forma permisible para este propósito es mediante la acción popular, cuyo ejercicio aún no está expedito por la carencia de su reglamentación". Vale decir, que la única vía permisible para solicitar la invalidez genérica de un Decreto Supremo es la Acción Popular que faculta el artículo 133 de la Ley Fundamental (23).

b) Un caso análogo es el Habeas Corpus interpuesto por la firma Picasso Hermanos Sociedad Anónima "contra los empleados de la Caja de Depósitos y Consignaciones, División de Alcoholes, como ejecutores del reglamento de la Ley 15387 sobre Timbres de la Bebida (ya que) desnaturaliza y sobrepasa los alcances de ella con infracción del inciso 8o. del artículo 154 de la Constitución, ya comprendiendo en la Ley a piscos $\mathrm{y}$ aguardientes que la ley les escluye, imponiendo severas sanciones, ya limitando el contenido de los envases $y$ restringiendo la movilización de sus productos para ser embotellados en otras plazas". En este proceso, el propio Tribunal Supremo, con fecha 14 de julio de 1966, declaró improcedente el habeas corpus incoado, porque se trataba de la declaración de inconstitucionalidad de un Reglamento de carácter general $y$ no de un caso. determinado, acción que debió hacerse valer al amparo de los artículos 133 de la Carta y su reglamentario 7o. de la Ley Orgánica del Poder Judicial (24).

9.- La legislación, jurisprudencia y doctrina extranjeras (25), ya tienen establecido desde antaño que cuando se ejercita la Acción Popular, los efectos de ésta son los de anular las normas acusadas. Asi pues, Venezuela desde el siglo pasado viene declarando la invalidez de disposiciones inconstitucionales a solicitud de cualquier persona del pueblo $\mathrm{V}$ aún de oficio. Colombia por ley de 1904, luego por Acto Legislativo No. 3 de 1910 y en el actual art. 214 de su Carta Fundamental, tiene establecida la Acción Popular a favor de cualquier persona, para declarar la inexequibilidad de las normas inconstitucionales o ilegales. Cuba en su Carta de 1940 estableció la acción pública, ejercida por no menos de 25 ciudadanos, con igual propósito; disposiciones todas éstas que no han quedado en el olvido, como en nuestro país, sino que los Tribunales de Justicia las aplican constantemente. Asi tenemos que en diciembre de 1971: Colombia declaró la inexequibilidad del Estatuto de Capitales de dicho país.

10.- Si se concede Acción Popular a cualquiera del pueblo, sin que se le haya conculcado algún derecho, obvio resulta que éste no buscará que se le declare inaplicable la disposición infractoria a su persona, puesto que nunca se le pretendió aplicar $y$, probablemente, no se le aplique jamás, Lo que solicitará más bien del Poder Judicial (en beneficio de la comunidad y buscando la intangibilidad de la Constitución y protección de las leyes) es la nulidad de aquellas normas secundarias, puesto que lo contrario carecería en lo absoluto de sentido.

11.- Así como mediante la Acción Popular se ataca directamente, en vía de acción, una disposición legal secundaria, el recurso a que se contrae el artículo XXII del Tít. Prelim. del Código Civil, aclarado por el numeral 8o. de la Ley Orgánica del Poder Judicial, aún vigente, tiene por finalidad declarar que una determinada disposición legal es inaplicable a un caso concreto por contravenir la Constitución o las leyes. En realidad, no es ólo un recurso, sino antes que nada una facultad del juzgador para declarar, aún de oficio, la inaplicabilidad de una determinada norma legal, $y$, al hacerlo, puede $y$ debe buscar la norma correcta aplicable al caso que se resuelve (26).

Comparar la Acción Popular con el recurso de inconstitucionalidad en sus efectos, resulta totalmen. te ilógico, ya que si con el segundo se puede pedir la inaplicabilidad de un Decreto Supremo, Reglamento o Resolución, no es dable que exista una acción para lograr lo mismo y ejercitada por cual-

(23) García Belaúnde, Domingo... "El Habeas Corpus Interpretado"; Lima; 1971 ; p.p. 195-196.

(24) Op. cit.; p. 211-212.

(25) Bielsa, Rafael... Op. cit.; Cap. 1; p.64 - A. Capote "Lecciones de Derecho Constitucional", p. 226, entre otros autores.

(26) Al respecto véase: a) Manuel Benigno Valdivia, "Memoria publicada en los Anales Judiciales de la Cokte Suprema de 1945; p. 489; b) el informe publicado en la edición de la citada Ley Orgánica del Poder Judicial; p. 82. 
quiera del pueblo. Mientras que las disposiciones del artículo XXII del Título Preliminar del Código Civil y 80 . de la Ley Orgánica del Poder Judicial se constriñen a la preferente aplicación de la norma constitucional sobre la legal conflictiva en la resolución del caso particular en juzgamiento, la acción confia. da a la iniciativa popular, al no estar dada sólo al titular del derecho conculcado, origina que el demandante, pida la nulidad de la norma legal secundaria que colida con las de rango superior, porque el criterio de tal instituto es el de liberar a los del pueblo (mediante una sola declaración del órgano competente) del cumplimiento de algún decreto gubernativo o resolución de carácter general.

Otra diferencia sustancial que existe entre am. bos institutos es que mientras que el recurso de inconstitucionalidad está dado básicamente contra las leyes, el segundo sólo cabe incoarse contra decretos o actos de inferior jerarquía, mas no contra las disposiciones del Poder Legislativo. El uno procede aún de oficio, el otro a petición de cualquiera del pueblo.

Siendo esto asi y estando legislado uno y otro instituto en forma procesal en los artículos 70 . y 8o. de la Ley Organica del Poder Judicial, no puede cabe duda sobre las diferencias que entre ambos existen.

12.- El propio trámite de puro derecho que se ha establecido indica que no será otra la cuestión a debatirse que la incomipatibilidad de la legislación y la declaración de invalidez de la norma de rango inferior. No hay hecho alguno ni agravio concreto que ventilar y recepcionar a prueba.

13.- Si se pensase que mediante la Acción Popular sólo puede pedirse la inaplicabilidad de la norma que se acuse, llegaríamos a la conclusión de que sólo podría solicitarse aquéllo respecto de los decretos gubernativos, reglamentos y resoluciones de carácter general, pero no contra las leyes, por no permitirlo la Constitución. Profundizando aún más, el artículo XXII del Tit. Prelim. del Código Civil y el numerat 8o. de la Ley Orgánica del Poder Judicial, resultarian atentatorios de la Carta, puesto que conforme al artículo 133 de ésta, los jueces deberían aplicar todas las leyes sin cuestionarse su constitucionalidad y tan sólo estarían facultados para no aplicar las normas inferiores que emanasen del Poder Ejecutivo. Esto no es lo real, puesto que como ya reiterada jurisprudencia lo tiene establecido, aún las leyes pueden dejar de aplicarse en razón de su inconstitucioṇalidad, ejercitándose este petitorio ya sea en la demanda o en cualquier estado del juicio, basándose en los precitados dispositivos del Código $\mathrm{Ci}$ vil y la Ley Orgánica del Poder Judicial ( y no en lo establecido en el artículo 133 de la Carta).

14.- Son tan diferentes los trámites $y$ efectos de las acciones de inaplicabilidad y nulidad, que la ley últimamente citada los regula en artículos separados.

Si ambos tuvieran un mismo objetivo bastaría con uno solo de ellos en que se estableciese el recurso de. inconstitucionalidad, aclarándose expresamente que procedería ejercitarse en vía de acción o de excepción en juicio. Más aún, resulta un contrasentido el que, teniendo ambos un mismo fin, tengan el uno (art. 8o.) la posibilidad de elevarse en consulta las sentencias definitivas y el otro (art. 7o.) carezca de este modo de revisión.

15.- Se argumenta que las sentencia tienen efecto sólo entre. las partes en litigio $y$, por lo mismo, no pueden declarar la nulidad erga-omnes de un decreto, reglamento o resolución, pero se olvida que este principio rige tan sólo para las acciones de naturaleza privada y no cuando se está frente a acciones públicas y de carácter constitucional.

Se olvida, también, que el actor no demanda a nombre y derecho propios sino en favor del pueblo y la pretensión no depende sólo de su exclusiva voluntad (como veremos), sino que lo que está en juego son tanto el interés de la comunidad que la Constitución se cumpla, como derechos y obligaciones públicos. Igualmente, no se tiene en cuenta que, siendo el Estado parte en estos procesos, mediante la sentencia se le va a obligar a que en lo sucesivo no aplique la norma inconstitucional en ninguna de sus dependencias, vale decir una anulación ex-nunc.

16.- Téngase además en cuenta que la nulidad extrínseca o formal está expresamente señalada en los artículos 26 y 27 de la Ley de 26 de setiembre de 1862 y en el numeral 166 de la actual Ley Fundamental, por lo que los actos del Gobierno que no cumplan con los requisitos preceptuados adolecen de nulidad.

17.- Para precisar los efectos de la Acción Popular no debe olvidarse tampoco lo prescrito en el art. 10. de la Constitución cuando dice "El Poder del Estado... se ejerce por los funcionarios con las limitaciones que la Constitución y las leyes establecen" $y$ el artículo 19 de la misma indica que "Son nulos los actos de los que usurpan funciones públicas y los empleos $\sin$ los requisitos que prescriben la Constitución y las leyes", con lo que están vicia- 
dos de nulidad los reglamentos, decretos y resoluciones de carácter general de la República que amplíen, modifiquen, deroguen o desconozcan las leyes existentes, incurriendo en exceso de poder $y$ falta de competencia. Si esto es asi, no hay razón alguna para que cualquier miembro de la comunidad no pueda acudir al Poder Judicial solicitando la declara. torio respectiva.

18.- No se interfiere con la Acción Popular las facultades del Poder Ejecutivo, ya que mediante la sentencia correspondiente no se deroga ni modifica el sentido del decreto para ajustarlo a las normas superiores, sino que, simplemente, se anula los efectos del mismo hacia el futuro.

19.- No se restringe tampoco la facultad del ciudadano -si fuera parte agraviada- para solicitar acumulativamente en su acción el petitorio de inaplicabilidad y que se le reconozca y restituya el derecho conculcado.

20.- Quienes sostienen la tesis de la no aplicación a un caso concreto, se basan en que las normas impugnables son sólo aquéllas que lesionan derechos de particulares y que éstos son los que, dado el caso, pueden solicitar en vía de acción que no se les aplique dichas prescripciones legales; pero resulta que existen decretos $y$ resoluciones que, sin vulnerar derechos de particulares, afectan los intereses del Estado y de la Comunidad en general, como fue el decreto dictado el 6 de agosto de 1948 convocando a una Asamblea Nacional con el carácter de Constituyente o como pueden ser los que, a pesar de prohibición legal expresa, creen u organicen una institución u organismo público, etc. Decretos éstos que no podrían ser impugnados por Acción Popular, ya que interés particular y directo sólo lo tendrá el Estado. Considero que como la Carta no distingue qué clase de reglamentos, decretos o resoluciones son factibles de invalidarse, nosotros no debemos distinguir alli donde ella no lo hace y como, además, esta acción está dada básicamente para proteger la constitucionalidad y la legalidad y evitar el exceso de poder, resulta clara la finalidad de laa acción que nos ocupa.

\section{1.- Desde cuándo rige la nulidad}

He aquí la segunda cuestión importante. Nada al respecto ha dicho la ley, por lo que, lógicamente, debemos admitir que el artículo 133 ha sido deficientemente legislado y reglamentado.

No es óbice esta carencia de norma para que el Juez decida desde cuándo son nulos los decretos tachados de inconstitucionales o ilegales. Este problema debe resolverse teniendo en cuenta el artículo XXIII del Tit. Prelim. del Código Civil, aplicando los principios generales del derecho.

En la jurisprudencia extranjera se ha solucionado el problema en el sentido de que la nulidad no puede tener fuerza retroactiva, o ex-tunc; la sentencia no puede anular desde sus origenes el decreto o resolución, sino que la declaratoria rige hacia el futuro. La Corte Suprema Colombiana (Acuerdo No. 3 de 17 de junio de 1915) manifiesta que las sentencias "Si tuvieran efectos retroactivos y alcanzaran a anular las leyes desde sus orígenes, ningún derecho habría firme y la inseguridad social y la zozobra serían permanentes y mayores cada día" (27). Igual criterio se ha sostenido en Italia y en muchos otros países donde la declaratoria de inconstitucionalidad tiene fuerza ex-nunc; esto es, hacie el futuro, $y$ si el actor (a quien se violaron derechos en base a la disposición inconstitucional) solicita la inaplicabilidad de la norma impugnada, se declara que ésta es nula en cuanto se pretendió aplicar a su persona y que, en consecuencia, no lo obliga. Nuestra jurisprudencia, o más bien, las sentencias expedidas por los Tribunales peruanos anulando decretos o reglamentos, no han tocado el problema, limitándose a declarar la invalidez.

Partimos del hecho que la declaratoria de nulidad -que técnicamente viene a ser anulabilidad- rige a futuro, pero pueden adoptarse básicamente 4 posiciones:

a) La norma es inválida desde que se interpone la demanda;

b) La norma es inválida desde que se senten. cia;

c) La norma es inválida desde que queda ejecutoriada la sentencia, sin perjuicio de su publicación en "El Peruano".

d) La norma es inválida desde su publicación en el Diario Oficial.

Parece poco sustentable establecer la fecha de interposición de la demanda como un hito para determinar desde cuándo rige la anulabilidad. Su único sustento sería que desde aquella fecha se opuso una

(27) Grant, James A.C. . "Estudio Cumparativo de los Sistemas de Control de Constitucionalidad de las Leyes", en la Revista de la Universidad Nacional de Jurisprudencia; México D.F.; Tomo VIII; No. 32; p. 129. 
persona a la disposición anulada; pero no es suficiente, ya que con igual criterio podría argumentarse cualquier fecha. Ningún país ha aceptado este parecer, dado que hay otros más valederos.

La Constitución Cubana de 5 de julio de 1940 ha adoptado el segundo, cuando dice: "En todo caso la disposición legislativa o reglamentaria o medida gubernativa declarada inconstitucional se considerará nula y sin valor ni efecto desde el día de la publicación de la sentencia en los estrados del Tribunal" (Art. 194, in fine) pero obliga, además, al Organismo, autoridad o funcionario que la dictó a derogarla de inmediato. Parece ser que no veían suficiente la declaratoria de nulidad y pensaron complementarla o reforzarla con la derogatoria de la norma anulada, incurriéndose así, técnicamente, en una aberración jurídica, ya que lo nulo no se puede derogar.

El criterio de que la nulidad opere desde que se dicte la sentencia aun cuando doctrinariamente puede ser sustentable, en la práctica no es aconsejable ya que la norma anulada, por su propio carácter general va a continuar aplicándose si no en la Capital, será en provincias, donde puede pasar mucho tiempo sin que se sepa de tal anulación.

Para las partes -en litigios comunes- puede ser válido este parecer, pero no en un caso como el presente en el que la sentencia va a tener una amplitud erga-omnes.

El tercer criterio es el más certero $y$ me inclino a su favor. No conozco sistema legal que lo haya aplicado, pero parece ser que en el nuestro sería el más apropiado. Desde que se dicta la sentencia definitiva hasta que la resolución baja a primera instancia $y$ el Juez ordena el cumplimiento de lo ejecutoriado $y$ se notifique al actor $y$ al Procurador General de la República, pasa el tiempo suficiente para que se conozca con amplitud la sentencia que dicte el máximo tribunal. El Procurador del ramo respectivo se habrá enterado. mucho antes de la sentencia, dado que por Ley las resoluciones se publican resumidas al día siguiente en el Diario Oficial "El Peruano" y tendrá tiempo suficiente para comunicar a quien corresponda, formal o informalmente, de tal anulación. Además, dada la notoriedad de la sentencia, los órganos de prensa darán también a conocer esa resolución. A mayor abundamiento, en el interin - desde que se dicta la sentencia hasta que se notifica el "cúmplase lo ejecutoriado" - hay tiempo suficiente para que se publique en el Diario Oficial "El Peruano" la Ejecutoria y para que el Ejecutivo se abstenga de aplicar en lo sucesivo la norma invalida- da.

En síntesis, la anulación opera desde que se notifica el "cúmplase lo ejecutoriado", sin perjucio de la pronta publicación de la ejecutoria respectiva.

Opino que, además, se debe enviar al Diario Oficial copia de la resolución pronunciada, para que, en un breve plazo y bajo responsabilidad, se cumpla con publicarla. Igualmente, debe enviarse circulares a las Cortes Superiores y Juzgados para que no apliquen en el futuro la norma invalidada, oficiándose al mismo tiemp al Ministro del ramo, comunicándole to resuelto por el Tribunal, tal como se hizo al resolver una consulta en el acuerdo de Sala Plena de 24 de abril de 1947.

Los Tribunales de Segunda Instancia deben hacer las gestiones pertinentes a fin de que, a la brevedad posible, se publique la Ejecutoria Suprema en los diarios de la provincia donde se hagan los avisos judiciales.

La cuarta posición no es aconsejable, a pesar de que teóricamente es perfecta, puesto que dependiendo el Diario Oficial "El Peruano" del Ejecutivo, éste puede demorar dolosamente la publicación de la materia $\mathrm{y}$, por consiguiente, manetener vigente por un mayor lapso su decreto, reglamento o resolución anulado. En nuestro país es sostenida por Raúl Ferrero Rebagliati (28) cuando propone un artículo ampliatorio de la Constitución del siguiente tenor: “... Cuando el Tribunal declara la inconstitucionalidad de una norma legal, ésta deja de tener eficacia desde el día siguiente de la publicación de la decisión". Italia ha recogido también esta posición en el art. 136 de la Constitución de 1948. (29) Si bien la tercera opción cabría basándose en disposiciones del Código de Procedimientos Penales, la última, de aceptarse, requeriría de una disposición legal expresa, por lo que no puede admitírsele.

Con relación al Poder Judicial, en causa alguna debe aplicar las normas invalidadas, ni el Ejecutivo puede propender a su aplicación, ya que contra las órdenes o disposiciones administrativas que pretendan continuarlas aplicando, procedería, si se violan derechos individuales o sociales, la interposición del habeas corpus (30).

(28) Ferrero Rebagliati, Raúl... "El Control de la Constitucionalidad de las Leyes", en Revista Jurídica del Perú; 1960; p. 91.

(29) Biscaretti de Ruffia, Paolo... "Derecho Constitucional"; p. 568-572.

(30) De este parecer es Bustamante Cisneros y asi lo manifiesta en su Discurso pronunciado como Presidente de la Corte Suprema que obra inserto en los Anales Judiciales de 1958; p. 318. 